\title{
Aplicação de Dados Eletromagnéticos na Bacia do Parnaíba para Prospecção de Água Subterrânea (Aquífero Serra Grande) no Estado do Piauí \\ ${ }^{*}$ Pedro H. S. Chibane ${ }^{1,2}$, Felipe L. Cavalcante ${ }^{1,3}$, Carlos A. Mendonça ${ }^{1}$, Oderson Souza Filho ${ }^{4}$
}

${ }^{1}$ IAG/USP, ${ }^{2}$ Convênio IAG/USP-CPRM/SUREG-SP, ${ }^{3}$ PIBIC-CNPq, ${ }^{4} \mathrm{CPRM}-\mathrm{PR}$

Copyright 2014, SBGf - Sociedade Brasileira de Geofísica

Este texto foi preparado para a apresentação no VI Simpósio Brasileiro de Geofísica, Porto Alegre, 14a 16 de outubro de 2014. Seu conteúdo foi revisado pelo Comitê Técnico do VISimBGt, mas não necessariamente representa a opinião da SBGf ou de seus associados. É proibida a reprodução total ou parcial deste material para propósitos comerciais sem prévia autorização da SBGt.

\section{Abstract}

Despite affected by extended dry seasons, the state of Piauí in Northeastern Brazil has groundwater resources that in principle can attend public, industrial and agricultural provision. Therefore, it is of great importance to develop exploration techniques to improve location of favorable places for drilled water wells. To guide field exploration, an experimental electromagnetic survey (slingram method) was conducted by CPRM-Geological Survey of Brazil - nearby the town of São Bráz, severely affected by 2012-2014 droughts. Here we present results from this experimental profile aimed to characterize the Serra Grande Aquifer, a major regional entity of the Paleozoic Parnaiba Basin. Our results, based on data inversion for a layered resistivity model, show that relevant structures for groundwater exploration can be recognized, suggesting the applicability of the method in further investigations.

\section{Introdução}

A região nordeste sofre com problemas de abastecimento de água, especialmente na porção semiárida, tornandose de grande importância os recursos subterrâneos tanto em terrenos cristalinos quanto sedimentares (Vasconcelos et al, 2012). O aquífero Serra Grande, um dos principais aquíferos da Bacia do Parnaíba, tem zona de recarga localizada desde Paranaguá, no sul do Piauí, até próximo ao município de Parnaíba, no extremo norte do estado, totalizando aproximadamente $950 \mathrm{~km}$ de extensão e $67 \mathrm{~km}$ de largura na porção central (Vasconcelos et al, 2012). O aquífero Serra Grande é confinado no topo, pelos folhelhos da Formação Pimenteiras e sua base assenta-se diretamente em rochas Pré-Cambrianas.

Em algumas regiões do semiárido, a água subterrânea é bastante salina, impossibilitando seu uso in natura para o consumo humano. Outro fator que dificulta a utilização dos aquíferos mais rasos decorre de sua variação sazonal (Vasconcelos et al, 2012), fazendo com que o nível freático varie conforme a época do ano, podendo secar alguns poços. Um conhecimento detalhado do substrato deve ser considerado ao se definir locais de captação (perfuração de poços), de forma a se obter um abastecimento regular.
A fim de testar a prospecção eletromagnética para recursos hídricos no aquífero Serra Grande, o Serviço Geológico do Brasil (CPRM) realizou um perfil experimental com o método slingram, no município de São Bráz, na região sudoeste do Piauí, conforme Figura 1.

Neste trabalho, apresentamos a interpretação deste perfil experimental para verificar se a inversão de dados de sondagem eletromagnética é capaz de delinear uma sucessão de unidades geoelétricas que pode ser correlacionada com as formações geológicas descritas na região. Mais especificamente, para averiguar se uma investigação com o método slingram permite caracterizar o aquífero Serra Grande, de forma a determinar locais em que o aquífero é mais espesso (maior potencial de armazenagem), mais raso (acessibilidade na captação por poços) e, se possível, inferir a qualidade da água subterrânea em termos da sua concentração em sais.

\section{Metodologia/ Problema Investigado}

O método slingram (Nagibhian, 1991) utiliza duas bobinas (uma transmissora, Tx, outra receptora, $\mathrm{Rx}$ ) separadas por um cabo que determina a separação entre as bobinas e serve como referência para determinar o atraso de fase entre a corrente que circula na bobina Tx e a força eletromotriz medida na bobina $R x$. As bobinas podem se configurar de maneiras diversas (na horizontal e vertical), com os campos aplicados na bobina Tx cobrindo uma faixa de frequência desde Hertz até quilohertz. A profundidade de investigação depende da separação entre as bobinas, a faixa de frequência utilizada e a condutividade do meio investigado.

No método slingram, o sinal medido é dado em termos do campo eletromagnético secundário normalizado pelo campo primário. A resposta eletromagnética possui componente real e imaginária: a componente real é também denominada de "em fase" e a imaginária de "quadratura". Para ambos componentes, o resultado é expresso em porcentagem em relação ao campo primário. 

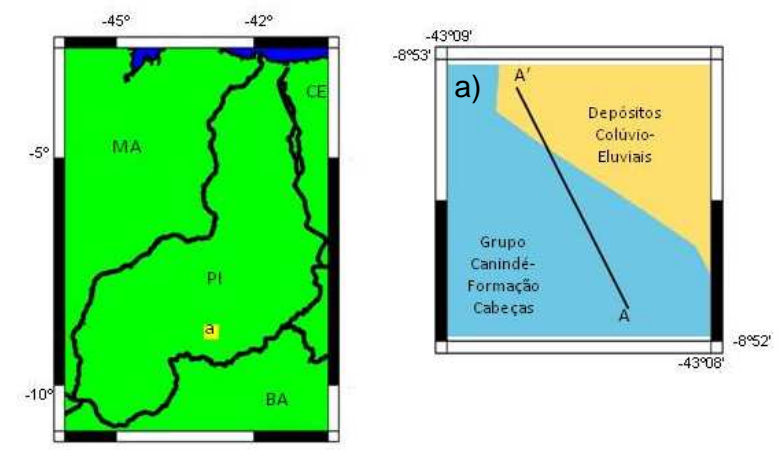

Figura 1- Localização do perfil eletromagnético ( $A$ - $A^{\prime}$ ) interpretado neste trabalho e unidades aflorantes $d a$ Bacia do Parnaíba.

O aparelho PROMIS-10 (Iris Instruments), utilizado na aquisição de dados no método slingram, opera com frequências de $110 \mathrm{~Hz}$ até $56 \mathrm{kHz}$. O transmissor Tx tem capacidade de gerar momento de dipolo entre $15 \mathrm{~A} \cdot \mathrm{m}^{2} \mathrm{e}$ $360 \mathrm{~A} \cdot \mathrm{m}^{2}$ a partir de uma bobina de $75 \mathrm{~cm}$ diâmetro, dependendo da frequência utilizada (maior a frequência, menor o momento de dipolo). O transmissor também possui inclinômetros para alinhamento com a horizontal. $\mathrm{O}$ receptor $\mathrm{Rx}$ tem dimensões de $30 \times 15 \times 20 \mathrm{~cm}$ e seu sistema mede, com uma resolução de $0,01 \%$ do campo primário, as três componentes do campo $(\mathrm{Hx}, \mathrm{Hy}$ e $\mathrm{Hz})$ e a corrente. O receptor $\mathrm{Rx}$ possui dois inclinômetros digitais e entrada para registro de posição (GPS).

No perfil experimental realizado pela CPRM, a separação entre as bobinas foi de $200 \mathrm{~m}$, totalizando assim 15 pontos de leitura, nas frequências de 440, 880, 1760, 3520 e $7040 \mathrm{~Hz}$. Cada medida demanda aproximadamente $50 \mathrm{~s}$, considerando as cinco frequências utilizadas. A escolha do perfil AA' (Figura 1) foi para confirmar a presença de estrutura rúptil identificada em imagens de satélite e por estar situado a uma distância economicamente viável para o transporte da água à sede de São Bráz. Os dados brutos podem ser apresentados na forma de pseudo-seções de resistividade que, dependendo da situação a ser estudada, auxilia na determinação das estruturas no substrato. Para este trabalho, os dados adquiridos foram processados com filtro gaussiano para diminuir a interferência por ruídos e os resultados podem ser apresentados em forma de pseudo-seção ou de gráficos "em fase" ou de "quadratura", utilizando o programa EMIGMAv8.6 (PetRos EiKon Inc.).

\section{Inversão de dados e análise de incerteza}

A inversão dos dados tem como objetivo determinar um modelo de resistividade para o substrato. Para dados EM com o método slingram, a inversão configura um problema não-linear que é resolvido iterativamente até obter um modelo de resistividade que se ajusta aos dados medidos. Como mostra a Figura 2, o modelo de camadas é caracterizado por parâmetros (espessuras e resistividades) e, para cada estação de medida, um modelo de camada pode ser determinado, sob vínculo de que os parâmetros que caracterizam os modelos em sondagens adjacentes sejam semelhantes.

O programa de inversão utilizado neste trabalho (EMIGMA) permite fixar (ou manter dentro de uma faixa) os parâmetros de profundidade ou resistividade de forma a fornecer soluções compatíveis com dados de geologia e perfilagem de poço (se existentes). Não havendo dados de poço, dados regionais podem ser utilizados definindo faixas de variação para cada parâmetro segundo valores médios. a)

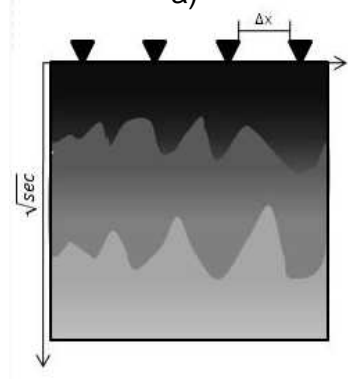

b)

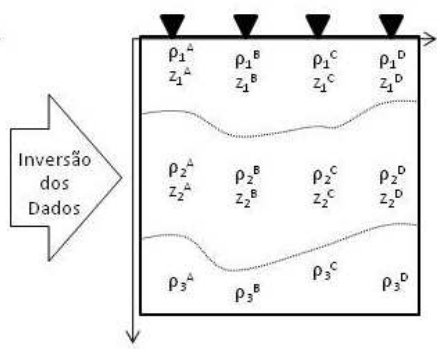

Figura 2- Esquema do processo de inversão utilizando o programa EMIGMA. Representação na forma de pseudoseção (a) e modelo geoelétrico (b) obtido com a inversão dos dados. Na pseudo-seção o eixo vertical (profundidade) é mostrado em termos da raiz do período. No modelo geoelétrico o eixo vertical expressa a profundidade (z) das camadas e suas resistividades $(\rho)$.

\section{Resultados}

A Figura 3 mostra os resultados obtidos com a interpretação do perfil experimental com o método slingram, medido no município de São Bráz-PI.

A Figura 3a mostra a pseudo-seção de resistividade na qual uma sucessão de unidades geoelétricas pode ser reconhecida, gradando de resistivas na superfície para condutivas em profundidade. $\mathrm{Na}$ pseudo-seção, a profundidade não é especificada e a transição entre as unidades geoelétricas se dá de forma difusa.

A Figura 3b, por outro lado, mostra uma solução particular fornecida pelo programa EMIGMA. Nesta seção as profundidades (e espessuras das camadas) podem ser inferidas, bem como os valores de resistividade para cada unidade. $O$ critério de inversão conjunta para todas as 15 estações com sondagem EM permite que os parâmetros identificados garantam a continuidade lateral das unidades geoelétricas.

A Figura 3c apresenta valores médios e desvio-padrão para um conjunto de 10 soluções obtidas, todas garantindo o ajuste aos dados com resíduo RMS (root mean square) menor que $10 \%$. Cada solução foi obtida partindo-se de modelos iniciais ligeiramente diferentes, 
dentro de uma faixa de valores de resistividade representativas para as unidades geológicas da região.

\section{Discussão e Conclusão}

Os resultados na Figura 3 mostram uma camada mais rasa bastante resistiva com resistividade média de $880 \pm 172$ ohm.m, seguida de uma camada com resistividade de $38 \pm 17 \mathrm{ohm} . \mathrm{m}$ e, mais ao fundo, uma camada condutiva com valor de $4 \pm 4$ ohm.m. Comparando o modelo de resistividade obtido na inversão de dados EM com a coluna estratigráfica descrita no local, pode-se inferir que a primeira camada geoelétrica (resistividade de $880 \pm 172$ ohm.m) associa-se à Formação Cabeças. O valor elevado de resistividade deve-se ao fato dos arenitos desta unidade serem pouco argilosos. A camada subjacente associa-se à Formação Pimenteiras, com resistividade de $38 \pm 17$ ohm.m, que é compatível com folhelhos. O Aquífero Serra Grande, abaixo dos folhelhos, aparece com resistividade de $4 \pm 4$ ohm.m.

a)

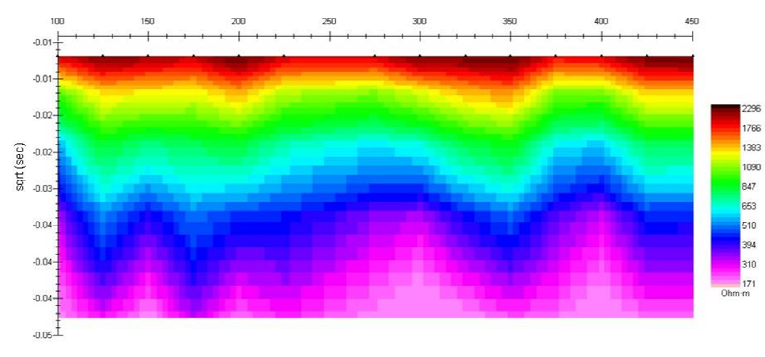

b)

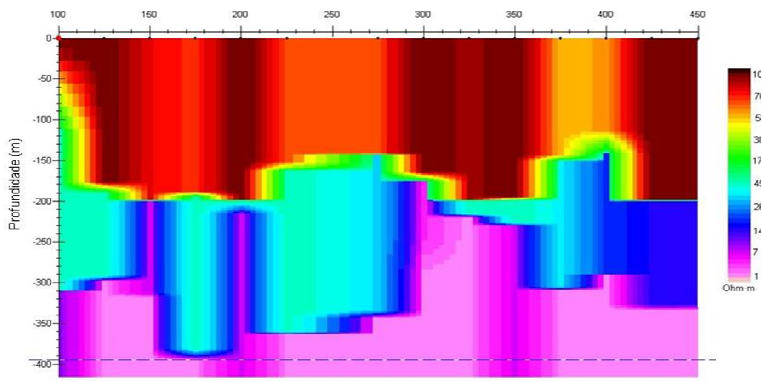

c)

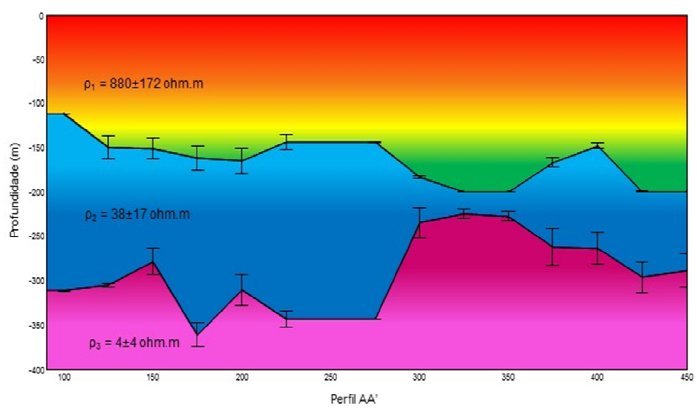

Figura 3 - Resultados da interpretação do perfil experimental A-A': (a) pseudo-seção de resistividade; (b) modelo geoelétrico obtido com o programa EMIGMA; (c) valores médios para 10 soluções (todas ajustando os dados com erro menor que 10\% RMS- root mean square).
Com base nas informações disponíveis, pode-se inferir que o Aquífero Serra Grande encontra-se mais próximo da superfície no trecho entre 300 e 350 metros do perfil. Em se tratando de uma exploração hidrogeológica com poços mais rasos, este trecho do perfil seria mais promissor, pois o aquífero está mais raso. Neste trecho do perfil, o topo do Serra Grande é identificado a cerca de $200 \mathrm{~m}$ de profundidade. Para efeito de comparação, no trecho de 100 a $300 \mathrm{~m}$ do perfil, a profundidade é superior a $300 \mathrm{~m}$. A variação relativamente abrupta do topo do arenito Serra Grande pode estar associada a estruturas descritas como "horst" (CPRM, 2009) na borda sudeste da Bacia do Parnaíba.

O valor de resistividade ( $\sim$ ohm.m) determinado para o Aquífero Serra Grande parece muito baixo para uma formação que, via de regra não apresenta salinidade elevada na água subterrânea, pelo menos na região de borda da bacia. Estudos posteriores, se possível utilizando perfilagem de poços e análise da água subterrânea, devem ser realizados para melhor caracterizar a resistividade elétrica das litologias que constituem o aquífero Serra Grande.

Em se tratando de um perfil experimental, os resultados obtidos neste trabalho mostram que o método slingram tem potencial para ser utilizado na prospecção de água subterrânea na Bacia do Parnaíba, em particular nas regiões de borda em que a profundidade do Serra Grande não excede uma ou duas centenas de metros. A possibilidade de se identificar estruturas "horst" pode ter implicações na escolha de locais para a captação de água subterrânea.

\section{Agradecimentos}

Ao convênio CPRM/IAG-USP №25256 pela oportunidade de realizar um trabalho que agrega conhecimento sobre a Bacia do Parnaíba com benefícios para a população local. Ao geofísico Luiz Gustavo Rodrigues Pinto, CPRM$\mathrm{SP}$, pelas sugestões ao revisar este resumo.

\section{Referências}

CPRM - Companhia de Pesquisa de Recursos Minerais. Projeto Borda Sudeste da Bacia Sedimentar do Parnaíba: relatório final. Teresina: CPRM-SUREG-RETE, 2009. 153p.; 2v., il (Programa Água Subterrânea para a Região Nordeste). Organização: Francisco Lages Correia Filho.

Nabighian, M. N., 1991. Electromagnetic methods in applied geophysics. II Series: Investigations in geophysics; no3. Society of Exploration Geophysicists. United States of America, Vol.2, Cap.3:105-270.

Vasconcelos, M. B., C. A. da Luz, M. A. A. Mourão, 2012. Projeto Rede Integrada de Monitoramento das Águas Subterrâneas: relatório diagnóstico Aquífero Serra Grande, Bacia Sedimentar do Parnaíba. Coordenação CPRM-Belo Horizonte, Brasil. Vol. 4: 47p. 